\title{
Article
}

\section{Influence of wheel size on muscle activity and tri-axial accelerations during Cross- country mountain biking}

Hurst, Howard Thomas, Atkins, Stephen, Metcalfe, John, Sinclair, Jonathan Kenneth and Rylands, Lee

Available at http://clok.uclan.ac.uk/15408/

Hurst, Howard Thomas ORCID: 0000-0001-7889-8592, Atkins, Stephen, Metcalfe, John ORCID: 0000-0002-8414-978X, Sinclair, Jonathan Kenneth ORCID: 0000-0002-2231-3732 and Rylands, Lee (2016) Influence of wheel size on muscle activity and tri-axial accelerations during Cross-Country mountain biking. Journal of Sports Sciences . ISSN 0264-0414

It is advisable to refer to the publisher's version if you intend to cite from the work. http://dx.doi.org/10.1080/02640414.2016.1215497

For more information about UCLan's research in this area go to http://www.uclan.ac.uk/researchgroups/ and search for <name of research Group>.

For information about Research generally at UCLan please go to http://www.uclan.ac.uk/research/

All outputs in CLoK are protected by Intellectual Property Rights law, including Copyright law. Copyright, IPR and Moral Rights for the works on this site are retained by the individual authors and/or other copyright owners. Terms and conditions for use of this material are defined in the policies page. 


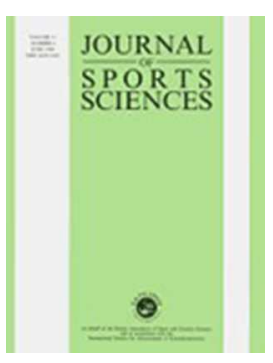

\section{Influence of wheel size on muscle activity and tri-axial accelerations during Cross-Country mountain biking}

\begin{tabular}{|r|l|}
\hline Journal: & Journal of Sports Sciences \\
\hline Manuscript ID & RJSP-2014-1186.R2 \\
\hline Manuscript Type: & Special Issue \\
\hline Keywords: & Vibration, Cycling, Mountain biking, electromyography \\
\hline \multicolumn{2}{|l}{} \\
\hline
\end{tabular}

SCHOLARONE ${ }^{\text {m }}$

Manuscripts 
1 Influence of wheel size on muscle activity and tri-axial accelerations during Cross-

2 Country mountain biking

3

$4 \quad$ Running head: Mountain biking and muscle activity

5 Keywords: vibrations, cycling, mountain biking, electromyography

6 Word Count: 3989

7

8

9 Acknowledgments

10 We would like to acknowledge Santa Cruz Bicycles in the USA and UK for the loan of the

11 test equipment and their support in this project. We would also like to confirm there were no

12 conflicts of interest and that Santa Cruz Bicycles' involvement was completely impartial. We

13 would also like to thank the participants for their time and effort in taking part in the study. 


\section{Abstract}

2

3 This study aimed to investigate the influence of different mountain bike wheel diameters on

4 muscle activity and whether larger diameter wheels attenuate muscle vibrations during cross-

5 country riding. Nine male competitive mountain bikers (age $34.7 \pm 10.7 \mathrm{yrs}$; stature $177.7 \pm$

$6 \quad 5.6 \mathrm{~cm}$; body mass $73.2 \pm 8.6 \mathrm{~kg}$ ) participated in the study. Riders performed one lap at race

7 pace on 26", 27.5 " and 29" wheeled mountain bikes. sEMG and acceleration (RMS) were

8 recorded for the full lap and during ascent and descent phases at the gastrocnemius, vastus

9 lateralis, biceps brachii and triceps brachii. No significant main effects were found by wheel

10 size for each of the four muscle groups for sEMG or acceleration during the full lap and for

11 ascent and descent $(\mathrm{p}>.05)$. When data were analysed between muscle groups, significant

12 differences were found between biceps brachii and triceps brachii $(\mathrm{p}<.05)$ for all wheel sizes

13 and all phases of the lap with the exception of for the 26 " wheel during the descent. Findings

14 suggest wheel diameter has no influence on muscle activity and vibration during mountain

15 biking. However, more activity was observed in the biceps brachii during 26" wheel

16 descending. This is possibly due to an increased need to manoeuvre the front wheel over

17 obstacles. 


\section{Introduction}

2

3 The physiological demands of cross-country mountain biking have been well reported over

4 recent years (MacRae, Hise, \& Allen, 2000; Lee, Martin, Anson, Grundy, \& Hahn, 2002;

5 Stapelfeldt, Schwirtz, Schumacher, \& Hillebrecht, 2004; Impellizzeri, Rampinini, Sassi,

6 Mognoni, \& Marcora, 2005; Prins, Treblanche, \& Myburgh, 2007). These studies focused

7 primarily on aerobic and anaerobic contributions to the activity. However, few studies have

8 investigated muscle activity during mountain biking. Hurst and Atkins (2006) proposed

9 mountain bike riders utilised a high level of isometric muscular contractions during racing to 10 aid postural control and control of the bicycle over obstacles.

12 Surface electromyography (sEMG) has been used to analyse muscle activity in road cyclists 13 (Egaña, Ryan, Warmington, \& Green, 2010; Matsuura, Arimitsu, Yuncki, \& Yano, 2011; 14 Blake, Champoux, \& Wakeling, 2012). However, these studies focused on lower limb muscle 15 activity and were laboratory based. Duc, Bertucci, Pernin, and Grappe (2008) investigated the 16 influence of hand grip position on the handlebar drops compared to the tops, during uphill 17 cycling on upper body muscle activity. However, the activity observed does not reflect those 18 used in mountain biking, due to the more dynamic nature of upper body movements. Hurst et 19 al. (2012) investigated the influence of course terrain on upper body sEMG during downhill 20 riding in elite downhill and cross-country cyclist. They found significant differences in the 21 muscles recruited between the groups, with downhill riders exhibiting greatest triceps brachii 22 activity, whilst cross-country riders showed greater activity in the brachioradialis. Their study 23 concluded that the differences in bicycle design between downhill and cross-country bicycles 24 may in part have influenced the differences observed. 
2 The standard mountain bike wheel diameter has long been 26 ". However, in the past 10 years

3 two more wheel size standards have been introduced, 29" and more recently 27.5 ". The

4 rationale for 29" wheels has been that the larger diameter improves roll over small trail

5 bumps and therefore improves contact with the ground and subsequent velocity. In addition,

6 it has been proposed by the cycling industry that the larger wheel will also reduce trail

7 vibrations observed in mountain biking (Levy \& Smith, 2005; Faiss, Praz, Meichtry, Gobelet,

8 \& Deriaz, 2007) being transmitted to the rider. Mester, Spitzenfeil, Schwarzer, \& Seifriz

9 (1999) found that these vibrations lead to increased muscle activity to aid dampening of trail

10 shocks, resulting in reduced exercise efficiency. Justification for the newer 27.5" wheel

11 standard has been that it potentially provides a balance between the better handling

12 characteristics of the 26 " wheel and the improved rolling properties of 29" wheels. However,

13 few academic studies exist determining the merits of these different wheel diameters on

14 performance. Macdermid, Fink, and Stannard (2014) did investigate differences in 3D

15 accelerations between 26" and 29" wheels and reported that 29" wheeled mountain bikes

16 resulted in significantly greater vibrations than the 26 " wheel during a typical lap of a cross-

17 country course, possibly due to the increase in velocity observed. However, Macdermid and

18 Stannard (2014) also point out that a key limitation of their study was that they used the same

1929 " bicycle fitted with 26 " wheels, thus potentially influencing their findings, as frame

20 geometry may not have been optimised for the smaller wheel size. In addition, they did not

21 investigate the influence of 27.5 " wheels. Therefore, the aims of this study were to

22 investigate the influence of the 3 primary wheel standards on tri-axial accelerations and

23 muscle activity in upper and lower limbs during cross-country mountain biking. It was

24 hypothesised that the larger wheel diameters would significantly attenuate the muscle activity

25 and vibrations experienced by the riders more than the 26 " wheel. 
2 Materials and methods

\section{Participants}

4 Nine male competitive mountain bikers (age $34.7 \pm 10.7 \mathrm{yrs}$; stature $177.7 \pm 5.6 \mathrm{~cm}$; body

5 mass $73.2 \pm 8.6 \mathrm{~kg}$ ) participated in the study. All riders had a minimum of 5 years racing

6 experience and competed at a National level in their respective age category. Ethical approval

7 was granted by the University of Central Lancashire Ethics Committee and in accordance

8 with the Declaration of Helsinki. Participants were informed both verbally and in writing of

9 the test procedures and written informed consent was obtained.

\section{Course Profile}

12 All testing was completed on a purpose build cross-country mountain bike course at the 13 British National Cycle Centre (Clayton Vale, Manchester). The course comprised of 14 undulating technical sections and also featured one major climb and descent, for which data 15 were analysed for these sections as well as the full lap. Figure 1 shows a global positioning 16 system (GPS) trace of the course and profile. A Garmin Edge 810 GPS computer was used to 17 record lap times and temperature. However, due to the level of tree cover and the 18 inaccuracies of GPS under tree cover, actual distances were recorded with a calibrated trundle 19 wheel. Distances of each section highlighted in figure 1 were; Start to $1=1.72 \mathrm{~km} ; 1$ to $2=$ $200.38 \mathrm{~km}(\mathrm{Climb}) ; 2$ to $3=0.47 \mathrm{~km} ; 3$ to $4=0.66 \mathrm{~km}$ (Descent); and 4 to Finish $=0.25 \mathrm{~km}$; 21 total lap distance $=3.48 \mathrm{~km}$. Based on Ordinance Survey maps, the average gradient of the 22 climb was $5.8 \pm 0.3 \%$, whilst the descent gradient was $-6.1 \pm 0.4 \%$. Testing took place over 23 a four week period between the months of June and July. Mean temperature was $18.5 \pm 1.5$ $24{ }^{\circ} \mathrm{C}$, with all test sessions being performed in sunny dry conditions. Therefore, course 25 conditions were consistent for all trials. 
$2 \quad * * *$ Figure 1 near here $* * *$

3

4 Surface EMG and Acceleration Analyses

5 Surface electromyography (sEMG) data were recorded using a mobile wireless sensor system

6 (Trigno Mobile, Delsys, USA) at $1926 \mathrm{~Hz}$ from the gastrocnemius, vastus lateralis, biceps

7 brachii and triceps brachii. Parallel bar electrodes with a $1 \mathrm{~cm}$ spacing between electrodes

8 were used. This method has been shown to significantly reduce the cross-talk between

9 muscles when compared to the use of disc electrodes (De Luca, Kuznetsoc, Gilmore, \& Roy,

10 2012). All recordings were taken from the left hand side of the body. Prior to sensor

11 placement, the skin was prepared by shaving the area, lightly abrading and cleaning with

12 alcohol wipes in order to minimise skin impedance. Though impedance was not measured, it

13 is accepted that this may have changed during testing due to sweating by the participants.

14 However, in order to ensure the same muscles were assessed during each trial, the sEMG

15 sensors were not removed between laps. Sensors were positioned longitudinally in parallel to

16 the muscle fibres on the medial aspect of each muscle. Placement of the sensors was in

17 accordance with the Surface EMG for Non-Invasive Assessment of Muscles project

18 recommendations. Once positioned on the muscles, sensors were secured in place using

19 elasticated bandages. Though the use of elasticated bandages may have possibly reduced

20 tissue movement artefacts, this would potentially improve indirect measurement of

21 acceleration on the skeletal system. In addition, during pilot testing, sensors did not stay in

22 situ using just hypoallergenic tape as a result of increased sweating. As such bandaging was

23 deemed the most appropriate method for securing the sensors. Following data collection,

24 sEMG data were full-wave rectified then filtered at $20 \mathrm{~Hz}$ using a second order low pass

25 Butterworth filter. 
2 According to Sinclair, Brooks, Edmundson, \& Hobbs (2012), due to the nature of field-based

3 testing, normalisation of sEMG signals to a maximal voluntary isometric contraction are not

4 possible or appropriate, though their study looked at running. This was due to the dynamic

5 muscular activity involved. Therefore, they proposed that sEMG data should be normalised to

6 a dynamic peak task, that being the peak amplitude recorded during the field-based trials. As

7 cycling is also dynamic in nature, sEMG data in the present study are presented as a

8 percentage of the dynamic peak task for the full lap and the ascent and descent sections.

10 In addition to sEMG, the Delsys Trigno sensors also recorded wireless tri-axial acceleration

11 for measurement of muscle vibrations. The placement of accelerometers on soft tissue to

12 monitor vibrations has previously been validated (Lafortune et al. 1995; Coza et al 2010).

13 Nokes, Fairclough, Mintowt, Mackie, and Williams (1984) also reported that vibrations could

14 be reliably and validly recorded with muscle mounted accelerometers if they were preloaded

15 to overcome the influence of soft tissue properties. Given the use of elasticated bandages to

16 secure the sensors, an element of preload would have been applied to the accelerometers,

17 though the exact force could not be determined. In addition, Ziegert and Lewis (1979) found

18 that lower mass accelerometers had a minimal effect data acquisition. Sensors used in the

19 current study were $14 \mathrm{~g}$ in mass. Data were sampled at $148.1 \mathrm{~Hz}$ with a range of $\pm 9 \mathrm{~g}$, and

20 analysed for total (XYZ) accelerations. Root mean squares (RMS) of the resultant XYZ data

21 were determined to analyse the vibrations experienced by the riders (ISO 1997). Similar

22 methods have been used in earlier studies of mountain biking vibrations (Macdermind et al.,

23 2014). Data were processed using EMGWorks Version 4.0 (Delsys Inc., Boston, USA) to 
1 determine mean sEMG and RMS for the full lap and the ascent and descent phases prior to

2 later statistical analyses.

\section{Protocols}

4 Following placement of the sensors participants were shown the course and allowed 1 hour to

5 familiarise themselves with the route. With the exception of one rider, all had previous

6 experience of racing or riding on the course used. Participants were required to complete one

7 lap of the course at self-determined race pace on each of the three wheel sizes. Thirty minutes

8 passive rest was given between trials to allow adequate recovery, this was then followed by a

910 minute re-warm, which consistent of low intensity cycling prior to the next trial. The test

10 bicycles were Santa Cruz Superlight full suspension mountain bikes (Santa Cruz Bicycles,

11 USA) with $120 \mathrm{~mm}$ and $100 \mathrm{~mm}$ of front and rear suspension respectively. All bicycles were

122014 models and were new and unused prior to the study. All three bicycles were fitted with

13 identical components, again new and unused, and differed component wise only in wheel

14 size, those being 26", 27.5" and 29" diameter. Tyre pressure was 35 psi for all trials.

16 Frame size was a medium for all three bicycles. However, overall bicycle mass differed due

17 to the differences in wheel diameter and wheel mass $(13.69 \mathrm{~kg}, 13.93 \mathrm{~kg}$ and $14.15 \mathrm{~kg}$ for the $1826 ", 27.5 "$ and 29" wheeled bicycles respectively). Therefore, to account for this and to 19 eliminate any potential influence on results, bicycle mass was standardised to the heaviest 20 bicycle (29" wheeled) by adding small weights to the lower downtube of the 26 " and 27.5 " 21 wheeled bicycles. Subsequently, any observed differences could be attributed more to rolling 22 properties of the different wheel diameters than any differences in mass. Top tube lengths 23 were 590, 602 and $613 \mathrm{~mm}$ for the 26", 27.5" and 29" wheels respectively, whilst bottom 24 bracket heights were 319, 326 and $337 \mathrm{~mm}$, respectively. To accommodate differences in 
1 rider stature a choice of two different stem lengths were offered (90 and $110 \mathrm{~mm}$ ). Saddle

2 setback was also adjusted to ensure best fit. In addition, riders were allowed to use their own

3 pedals. Suspension systems were set up according to the manufacturers' recommendations for

4 each rider's individual weight and to allow for 10 percent sag in the travel. Both front and

5 rear suspension were run in fully open mode, whilst shock leverage ratios were optimised by

6 the manufacturer for each frame geometry.

8 Immediately prior to each trial participants lined up on the start line and were instructed to 9 perform a maximal vertical jump to provide a marker on the accelerometer data. This was 10 used to synchronise the accelerometer and sEMG data. Participants were then set off $10 \mathrm{~s}$ 11 post vertical jump. All sEMG and accelerometer data pre and $10 \mathrm{~s}$ post jump were discarded 12 from the analysis. The time the participants crossed the finish line was noted and all data after 13 this time was also discarded from the results. In the absence of a trigger system to help 14 identify where the climb and descents started and ended on the sEMG and accelerometer 15 traces, data were synchronised with the time date on the GPS unit attached to the handlebars. 16 The start and end of the main climb and descent were marked with signposts. Riders were 17 instructed to press the 'lap' button on the GPS at the start and end of these sections. This then 18 enabled the identification these sections on the sEMG and accelerometer traces by means of 19 the time stamps. When determining mean data in the EMGWorks software, these time blocks 20 were identified and subsequently analysed. Participants were randomly assigned to three 21 groups of three participants and trials were counterbalanced for each group. 
1 Normality of data were first confirmed by means of a Shaprio-Wilk test. Differences in

2 muscle activity and accelerations between wheel sizes and between muscle groups within

3 each wheel size were determined using within groups one-way repeated measures ANOVA's.

4 Bonferroni corrections were used during post hoc analyses to control for type I errors. Where

5 the homogeneity assumption was violated, the degrees of freedom were adjusted using the

6 Greenhouse Geisser correction. Effect sizes were calculated using partial $\operatorname{Eta}^{2}\left(\mathrm{p}^{2}\right)$.

7 Significance was accepted at the $\mathrm{p} \leq 0.05$ level (Sinclair, Taylor, \& Hobbs, 2013) and data are

8 presented as mean \pm standard deviation. All statistical procedures were conducted using

9 SPSS 20.0 (SPSS Inc., Chicago, IL, USA).

11 Results

12 Though riders performed each lap at a self-determined race pace, no significant difference

13 was found for mean velocity between wheel sizes $\left(F_{(2,16)}=.70 ; p=.45 ; p^{2}=.08\right)$, with mean

14 values of $13.7 \pm .8(95 \% \mathrm{CI}, 13.1,14.3), 13.6 \pm .8(95 \% \mathrm{CI}, 13.0,14.2)$ and $13.9 \pm .8(95 \%$

15 CI, 13.3, 14.5) $\mathrm{km} . \mathrm{h}^{-1}$ being reported for the 26", 27.5" and 29" wheeled bicycles

16 respectively. Additionally, no significant differences were found in lap times between wheel

17 sizes $\left(\mathrm{F}_{(2,16)}=.69 ; \mathrm{p}=.45 ; \mathrm{p}^{2}=.08\right)$. Mean lap times were $916.1 \pm 54.5(95 \% \mathrm{CI}, 874.3$,

$18957.6), 923.8 \pm 52.9(95 \%$ CI, 883.1, 964.5) and $904.2 \pm 54.7(95 \% \mathrm{CI}, 862.1,946.3) \mathrm{s}$ for

19 the 26", 27.5" and 29" wheeled bicycles respectively.

\section{Surface electromyography data}

22 Analysis of sEMG data revealed no significant main effects for wheel size when analysed

23 over the full lap for the gastrocnemius $\left(\mathrm{F}_{(2,16)}=.29 ; \mathrm{p}=.75 ; \mathrm{p}^{2}=.04\right)$, vastus lateralis $\left(\mathrm{F}_{(2,16)}=\right.$ 
$\left.1 \quad 1.42 ; \mathrm{p}=.27 ; \mathrm{p}^{2}=.15\right)$, biceps brachii $\left(\mathrm{F}_{(2,16)}=.83 ; \mathrm{p}=.40 ; \mathrm{p}^{2}=.09\right)$ or triceps brachii $\left(\mathrm{F}_{(2,16)}\right.$ $\left.2=.12 ; \mathrm{p}=.89 ; \mathrm{p}^{2}=.02\right)$. When data were analysed for the climb alone, no significant main 3 effect was again reported for any muscle group by wheel size; gastrocnemius $\left(\mathrm{F}_{(2,16)}=.39 ; \mathrm{p}\right.$ $\left.4=.69 ; \mathrm{p}^{2}=.05\right)$, vastus lateralis $\left(\mathrm{F}_{(2,16)}=.95 ; \mathrm{p}=.41 ; \mathrm{p}^{2}=.11\right)$, biceps brachii $\left(\mathrm{F}_{(2,16)}=.44 ; \mathrm{p}\right.$ $\left.5=.65 ; \mathrm{p}^{2}=.05\right)$ and triceps brachii $\left(\mathrm{F}_{(2,16)}=.43 ; \mathrm{p}=.66 ; \mathrm{p}^{2}=.05\right)$ respectively. Analysis of 6 descent sEMG also found no significant main effect for wheel size; gastrocnemius $\left(\mathrm{F}_{(2,16)}=\right.$ $\left.7.23 ; \mathrm{p}=.80 ; \mathrm{p}^{2}=.03\right)$, vastus lateralis $\left(\mathrm{F}_{(2,16)}=1.64 ; \mathrm{p}=.23 ; \mathrm{p}^{2}=.17\right)$, biceps brachii $\left(\mathrm{F}_{(2,16)}=\right.$ $\left.8.94 ; \mathrm{p}=.37 ; \mathrm{p}^{2}=.11\right)$ or triceps brachii $\left(\mathrm{F}_{(2,16)}=.13 ; \mathrm{p}=.88 ; \mathrm{p}^{2}=.02\right)$. Table 1 shows the 9 mean values for sEMG as a percentage of dynamic peak task and 95\% CI. When muscles 10 were compared against each other within wheel sizes, significant differences $(p<.05)$ were 11 found between the antagonistic muscles of the biceps brachii and triceps brachii within all 12 wheel sizes when analysed over the full lap and the climb. However, during the descent 13 section significant differences $(\mathrm{p}<.05)$ were only reported between biceps brachii and triceps 14 brachii within the 27.5 " and 29 " wheel sizes.

***Table 1 near here***

\section{Acceleration Data}

19 Analysis of total XYZ acceleration amplitude (RMS) between muscles over the full lap 20 revealed no significant main effect for wheel sizes in the gastrocnemius $\left(\mathrm{F}_{(2,16)}=1.42 ; \mathrm{p}=\right.$ $\left.21.27 ; \mathrm{p}^{2}=.15\right)$, vastus lateralis $\left(\mathrm{F}_{(2,16)}=.48 ; \mathrm{p}=.63 ; \mathrm{p}^{2}=.06\right)$, biceps brachii $\left(\mathrm{F}_{(2,16)}=.85 ; \mathrm{p}=\right.$ $\left.22.45 ; \mathrm{p}^{2}=.10\right)$ or triceps brachii $\left(\mathrm{F}_{(2,16)}=.70 ; \mathrm{p}=.51 ; \mathrm{p}^{2}=.08\right)$. Data from the climbing section 23 also showed no significant main effect for wheel size; gastrocnemius $\left(\mathrm{F}_{(2,16)}=.87 ; \mathrm{p}=.44 ; \mathrm{p}^{2}\right.$ 
$1=.10)$, vastus lateralis $\left(\mathrm{F}_{(2,16)}=2.73 ; \mathrm{p}=.10 ; \mathrm{p}^{2}=.25\right)$, biceps brachii $\left(\mathrm{F}_{(2,16)}=1.50 ; \mathrm{p}=.25\right.$;

$\left.2 \mathrm{p}^{2}=.16\right)$ or triceps brachii $\left(\mathrm{F}_{(2,16)}=.90 ; \mathrm{p}=.43 ; \mathrm{p}^{2}=.10\right)$. Similarly, no significant main

3 effects were found for wheel size during the main descent section of the lap; gastrocnemius

$4 \quad\left(\mathrm{~F}_{(2,16)}=1.94 ; \mathrm{p}=.18 ; \mathrm{p}^{2}=.20\right)$, vastus lateralis $\left(\mathrm{F}_{(2,16)}=.68 ; \mathrm{p}=.52 ; \mathrm{p}^{2}=.08\right)$, biceps brachii

$5 \quad\left(\mathrm{~F}_{(2,16)}=.47 ; \mathrm{p}=.64 ; \mathrm{p}^{2}=.06\right)$ or triceps brachii $\left(\mathrm{F}_{(2,16)}=.51 ; \mathrm{p}=.61 ; \mathrm{p}^{2}=.06\right)$. When

6 muscles were compared against each other within each wheel size, significant differences

7 existed $(\mathrm{p}<.001)$ in total acceleration between the gastrocnemius and vastus lateralis as

8 expected during the full lap, climb and descent sections. However, no significant differences

9 in acceleration were found between the biceps brachii and triceps brachii for any section of

10 the course or over the full lap. Table 2 shows the mean total acceleration amplitude (RMS)

11 for each muscle and wheel size along with $95 \%$ CI.

***Table 2 near here***

\section{Discussion}

15 The purpose of this study was to determine the influence of three different mountain bike 16 wheel diameters on muscle activity and vibrations at different muscle sites during a typical 17 cross-country lap at race pace. The key findings were that no significant differences were 18 observed in muscle activity between the 26", 27.5" and 29" wheeled bicycles when analysed 19 for the full lap and during the highlighted ascent and descent sections. Similarly, no 20 significant differences were found in accelerations at the four different muscle sites between 21 the three wheel sizes. Therefore, the hypothesis that larger wheels reduce muscle activity and 22 vibrations should be rejected. However, other factors may also have influenced the results of 23 the current study. 
2 The present study found significantly lower sEMG values than those reported by Hurst et al.

3 (2012) in elite cross-country and downhill riders. Although the riders in the present study

4 were not performing at an elite level, the differences between these studies are less likely the

5 result of differences in athletic ability and more likely due to the limitation of normalising

6 muscle activity during dynamic tasks to a maximal voluntary isometric contraction. Mountain

7 biking involves numerous eccentric muscular contractions as a result of riding off drops to

8 aid dampening and control of the bicycle. This most likely resulted in the greater then

9 maximal voluntary isometric contraction values reported previously by Hurst et al. (2012).

10 However, the present study normalised on course muscle activity to the peak dynamic task

11 values elicited across all trials in accordance the methods previously reported (Sinclair et al.,

12 2012). Results showed that irrespective of wheel size, mean muscle activity over the full lap,

13 ascent and descent sections were not significantly different and represented a very low

14 percentage of peak dynamic task, approximately $2-6 \%$. This low percentage may potentially

15 be skewed somewhat due to high peak values occurring when riding off drops to help control

16 the bicycle. The course used contained several drops of approximately $1 \mathrm{~m}$ in height. In

17 addition, differences between the current study and that of Hurst et al. (2012) may also be

18 attributed to the different sEMG methodologies used and the use of disc electrodes by Hurst

19 et al. (2012), as opposed to the parallel bar electrodes used in the current study.

21 Though values did not reach a level of significance, the results show that biceps brachii 22 activity was generally higher during all phases of the lap for the 26 " wheel when compared to 23 the 27.5 " and 29" wheels. This may be the result of riders having to pull more on the handle 24 bars increasing elbow flexion to lift the front wheel of the 26" wheel over obstacles and small 
1 gaps. As a result of the larger wheel diameter, both the 27.5 " and 29" wheels would

2 potentially roll over such obstacles more efficiently and would not drop into small gaps as

3 easily, thereby reducing muscle activity. This supposition would appear to be supported when

4 data were analysed between muscle groups. Significant differences were found between the

5 antagonistic muscles of the biceps brachii and triceps brachii over the full lap and the main

6 climbing section for all wheel sizes. However, during the descent section, only significant

7 differences were found between these two muscle groups when riding the 27.5 " and 29 "

8 wheeled bicycles. The non-significant difference between biceps brachii and triceps brachii

9 during downhill on the 26 " wheel bicycles again potentially indicates a greater demand on the

10 biceps to manoeuvre the bicycle over and around obstacles. However, it is important to note

11 the relatively large standard deviations reported for the sEMG data. This may reflect

12 differences in riding styles of the participants, as riders may have adapted their riding styles

13 to suit the ride qualities of each bicycle. However, without video analysis of each ride, it is

14 difficult to quantify if or how much this differed between bicycles.

16 In addition, anthropometric differences may also have influenced the results and the large

17 standard deviations reported. Though not measured in the current study differences in limb

18 lengths between riders may have influenced these findings, as this would influence leverage

19 at the cranks and handlebars and thus affect how easily a rider could manoeuvre the bicycle

20 over or around trail obstacles. Given the lack of significant difference in mean velocity over

21 the course, difference between the three bicycles was less than $0.4 \mathrm{~km} \cdot \mathrm{h}^{-1}$, it is less likely that

22 would have influenced the muscle activity and vibrations encountered by the riders. 
1 Lastly, upper limb sEMG may also have been influenced by braking activity. Hurst et al.

2 (2012) reported increased forearm activity in elite cross-country riders when compared to

3 downhill riders. This they proposed was possible the result of frame geometry differences and

4 smaller brake rotors. However, in the present study, equipment was the same on all bicycles

5 as was the head tube angle, therefore it is unlikely that these would have impacted on the

6 finding. Differences were more likely the result of riding style, as some riders may have

7 braked more into corners than other, resulting in the high standard deviations observed in

8 biceps brachii sEMG. Future research may seek to quantify the contribution of braking to 9 muscle sEMG activity.

11 Previous research has tried to evaluate the external load imposed on riders during mountain 12 biking (Hurst, Swarén, Hébert-Losier, Ericsson, Sinclair, Atkins, \& Holmberg, 2013). Their 13 study used a tri-axial accelerometer positioned between the scapulae. However, they reported 14 values as a global index of load/vibration on the whole body, which did not reflect the 15 vibrations exerted on specific muscle groups or joint. As such, the present study analysed 16 total acceleration (XYZ) (RMS) as an indicator of vibrations imposed on muscles in the 17 upper and lower limbs. Other than the expected differences in vibrations between the 18 gastrocnemius and vastus lateralis, due to the different locations from the body/bicycle 19 interface, no significant differences were found for muscles between wheel sizes or within 20 muscle groups. This is in contrast to the findings of Macdermid et al. (2014) who found the 2129 " wheel resulted in significantly greater vibrations than the 26 " wheeled mountain bike. In 22 addition, data for vibrations presented in the current study are approximately double the 23 magnitude of those reported by Macdermid et al. (2014). This may be the result of 24 differences in sensor placement, as Macdermid et al. (2014) positioned their accelerometers 25 on the bony processes of the wrist and ankle, whilst sensors in the present study were 
1 positioned on soft tissue on the medial aspects of the muscles to be analysed. Chiementin,

2 Rigaut, Crequy, Bolaers, and Bertucci (2012) also state that in order to assess vibrations in

3 cycling the accelerometers should be located at the machine-hand interface. Though this is a

4 valid point, within the present study positioning of the sensors in this region would have

5 prevented the ability to determine muscle activity, due to the multi-sensor nature of the

6 Delsys Trigno system. Therefore, these differences may account for much of the differences

7 between Macdermid et al. (2014) and the present study.

8 Research by Lafortune, Hening, and Valiant (1995) and Coza, Nigg, and Fliri (2010)

9 previously validated the use accelerometers placed on soft tissue to monitor vibrations on

10 human muscle. Lafortune et al. (1995) did however reported values approximately double the

11 amplitude of those recorded by accelerometers placed on the bone. Additionally, Kim et al.

12 (1993) also found that skin mounted accelerometers increased vibrations by approximately 12

$13 \%$ when compared to bone mounted accelerometers. Though it is generally believed that

14 muscle would act as a damper and attenuate the accelerometer signals, during exercise the

15 increased eccentric activity of the muscles upon landing forces, or those experienced during

16 descending and jumping in mountain biking in our case, have been shown to increase

17 intramuscular tension and therefore augment acceleration signals (Mizrahi, Verbitsky, \&

18 Isakov, 2000). This may in part account for some of the differences in results between the

19 current study and those of Macdermid et al. (2014). Arpinar-Avsar, Birlik, Sezgin, and Soylu

20 (2013) sought to quantify the vibrations imposed on the forearm of the rider when riding a

21 mountain bike. They reported RMS values for acceleration again approximately half those

22 reported in the present study. However, their study only involved riders riding over rough

23 road for a distance of $250 \mathrm{~m}$ and not terrain representative of off-road cycling. This most

24 likely contributed to the lower values reported. 
1 Differences may also be attributed to the fact that full suspension bicycles were used in the 2 present study compared to the rigid hard tail mountain bike used by Macdermid et al. (2014).

3 As a consequence, this may have influenced riding dynamics. It is possible that the lower

4 accelerations observed by Macdermid et al. (2014) may have resulted from greater flexion of

5 the arms and legs to absorb trail shocks more effectively, whilst in the present study riders

6 may have relied more on the bicycle's suspension to absorb the shocks. However, this 7 potentially could have led to participants riding with straighter arms and legs and 8 unknowingly increasing the vibrations transmitted to the muscles, possibly during the shocks 9 rebound phase. This idea may be supported by Hurst et al. (2012) who found downhill riders 10 had a smaller degree of elbow flexion compared to cross-country riders as a result of the 11 greater level of suspension travel used on downhill specific bicycles.

The non-significant differences in vibrations between the three wheel sizes in the present study may again be due to the effects of the suspension systems effectively reducing trail

15 shock. In addition to the lack of rear suspension on the bicycle used in the Macdermid study, 16 they also fitted the 26 " wheels to a frame designed for 29" wheels. This may have altered the 17 handling characteristics of the bicycle, as the bottom bracket and crank arms would have 18 been lower to the ground than when using frames designed specifically for the respective 19 wheel sizes.

\section{Limitations}

22 One potential limitation of the present study was the lack of gyroscopic and magnetometer 23 sensors within the sensor units used. The inclusion of such sensors could have aided in more 
1 accurate determination of the directionality of the acceleration forces experienced by the

2 riders. Such information could have helped identify differences in riding styles between

3 wheel sizes and whether riders were required to use greater lateral, vertical or horizontal

4 efforts to manoeuvre the bicycles through different sections of the course. In addition, the

5 inclusion of these sensors may have allowed the use of spectral analyses to determine the

6 frequency of vibrations in the vertical and horizontal planes, as with the current sensor

7 configuration and the movement of the riders it would have been practically impossible to

$8 \quad$ identify these vertical and horizontal frequencies.

\section{Conclusions and practical implications}

11 In conclusion, this study revealed that larger wheel diameters did not significantly reduce 12 muscle activity or vibrations more so than the long standing traditional 26 " wheel on the 13 particular course used. However, there appeared to be a trend for slightly greater biceps 14 brachii activity in the 26 " wheel. This could have been the result of the need to lift the front 15 wheel over small obstacles more or differences in rider anthropometrics or a combination of 16 both. Additionally, differences in riding styles or adaptations to riding the different wheeled 17 bicycles may have played a part in muscle activity. Ultimately, the lack of statistical 18 differences between the measured parameters suggests that when ridden by trained mountain 19 bike riders all three wheel sizes are just as effective at controlling trail induced shocks and 20 that bicycle choice is largely a matter of personal preference. Within a field based setting, 21 there are likely to be a number of factors that influence muscle activity rather than wheel size 22 alone. 


\section{References}

2 Arpinar-Avsar, P., Birlik, G., Sezgin, Ö.C., \& Soylu, A.R. (2013) The effects of surface3 induced loads on forearm muscle activity during steering a bicycle. Journal of Sports $4 \quad$ Science and Medicine, 12, 512-520.

5 Blake, O.M., Champoux, Y., \& Wakeling, J.M. (2012) Muscle Coordination Patterns for $6 \quad$ Efficient Cycling. Medicine and Science in Sports and Exercise, 44, 926-938.

7 Chiementin, X., Rigaut, M., Crequy, S., Bolaers, F., \& Bertucci, W. (2012) Hand-arm 8 vibration in cycling. Journal of Vibration Control, 19, 2551-2560.

Coza, A., Nigg, B.M., \& Fliri, L. (2010) Quantification of soft-tissue vibrations in running: accelerometry versus high-speed motion capture. Journal of Applied Biomechanics, 26, 367-373.

De Luca, C.J., Kuznetsoc, M., Gilmore, L.D., \& Roy, S.H. (2012) Inter-electrode spacing of surface EMG sensors: Reduction of crosstalk contamination during voluntary contractions. Journal of Biomechanics, 45, 555-561.

Duc, S., Bertucci, W., Pernin, J.N., \& Grappe, F. (2008) Muscular activity during uphill cycling: Effect of slope, posture, hand grip position and constrained bicycle lateral sways. Journal of Electromyography and Kinesiology, 18, 116-127. Physiology. 108, 649-656. 
1 Faiss, R., Praz, M., Meichtry, A., Gobelet, C., \& Deriaz, O. (2007) The effect of

2 mountain bike suspensions on vibrations and off-road uphill performance. Journal of

3 Sports Medicine and Physical Fitness, 47, 151-158.

Hurst, H.T., \& Atkins, S. (2006) Power output of field-based downhill mountain biking. Journal of Sports Sciences, 24(10), 1047-1053.

6 Hurst, H.T., Swarén, M., Hébert-Losier, K., Ericsson, F., Sinclair, J., Atkins, A., \& 7 Holmberg, HC. (2012) Influence of course type on upper body muscle activity in elite 8 cross-country and downhill mountain bikers during off road downhill cycling. Journal of $9 \quad$ Science and Cycling, 1(2), 2-9.

Hurst, H.T., Swarén, M., Hébert-Losier, K., Ericsson, F., Sinclair, J., Atkins, A., \& Holmberg, HC. (2013) GPS-based evaluation of activity profiles in elite downhill mountain biking and the influence of course type. Journal of Science and Cycling, 2(1), 25-32. Physiological correlates to off-road cycling performance. Journal of Sports Sciences, 23, $41-47$

Kim, W., Volshin, A.S., Johnson, S.H., \& Simkin, A. (1993) Measurement of impulsive bone motion by skim-mounted accelerometers. Journal of Biomechanical Engineering, $115,47-52$ and skin mounted transducers. Journal of Biomechanics, 28, 989-993. 
1 Lee, H., Martin, D.T., Anson, J.M., Grundy, D., \& Hahn, A.G. (2002) Physiological

2 characteristics of successful mountain bikers and professional road cyclists. Journal of

3 Sports Sciences, 20, 1001-1008.

Levy, M., \& Smith, G. (2005) Effectiveness of vibration damping with bicycle suspension systems. Sports Engineering, 8, 99-106.

Macdermid, P.W., Fink, P.W., \& Stannard R. (2014) Transference of 3D accelerations during cross country mountain biking. Journal of Biomechanics, 47, 1829-1827.

MacRae, H.S-H., Hise, K.J., \& Allen, P.J. (2000) Effects of Front and Dual Suspension Mountain Bike Systems on Uphill Cycling Performance. Medicine and Science in Sports and Exercise, Vol. 32, 1276-1280.

Matsuura, R., Arimitsu, T., Yuncki, T., \& Yuno, T. (2011) Effects of resistive load on performance and surface EMG activity during repeated cycling sprints on a nonisokinetic cycle ergometer. British Journal of Sports Medicine. 45, 820-824.

Mester, J., Spitzenfeil, P., Schwarzer, J., \& Seifriz, F. (1999) Biological reaction to vibration - implications for sport. Journal of Science and Medicine in Sport, 2, 211-226.

Mizrahi, J., Verbitsky, O., \& Isakov, E. (2000) Shock accelerations and attenuation in downhill and level running. Clinical Biomechanics, 15, 15-20.

Nokes, L., Fairclough, J.A., Minitowt, W.J., Mackie, I., \& Williams, J. (1984) Vibration analysis of human tibia: The effects of soft tissue on the output from skin-mounted accelerometers. Journal of Biomechanical Engineering, 6, 223-226. 
1 Prins, L., Terblanche, E., \& Myburgh, K.H. (2007) Field and laboratory correlates of

2 performance in competitive cross-country mountain bikers. Journal of Sports Sciences, $3 \quad 25,927-935$.

4 Saha, S., \& Lakes, R.S. (1977) The effect of soft tissue on wave-propagation and 5 vibration tests for determining the in vivo properties of bone. Journal of Biomechanics, $6 \quad 10,393-401$.

7 Sinclair, J., Brooks, D., Edmundson, C.J., \& Hobbs S.J. (2012) The efficacy of EMG 8 MVC normalisation techniques for running analyses. Journal of Biomechanics, 45(1), 9623.

10 Sinclair, J., Taylor, P.J., \& Hobbs, S.J. (2013) Alpha level adjustments for multiple 11 dependent variable analyses and their applicability - A review. International Journal of 12 Sport Science and Engineering, 7, 17-20.

13 Stapelfeldt, B., Schwirtz, A., Schumacher, Y.O., \& Hillebrecht, M. (2004) Workload 14 demands in mountain bike racing. International Journal of Sports Medicine, 25, 294-300. 15 Ziegert, J.C., \& Lewis, J.L. (1979) The effects of soft tissue on measurements of 16 vibrational bone motion and skin-mounted accelerometers. Journal of Biomechanics, 101, $17 \quad 218$. 
2 Figure 1. GPS profile of course. Numbers indicate the different sections of the course.

3 
1

2 Table 1. Mean \pm standard deviation and $95 \%$ CI for mean sEMG amplitude as a percentage

3 of dynamic peak task for different wheel size during (A) full lap; (B) climb; and (C) descent.

4 *Significantly different to triceps brachii (26"); † significantly different to triceps brachii

$5 \quad(27.5 ”)$; $¥$ significantly different to triceps brachii (29”).

6 
2 Table 2. Mean \pm standard deviation and 95\% CI of mean acceleration amplitude (RMS) for 3 different wheel size during (A) full lap; (B) climb; and (C) descent. 


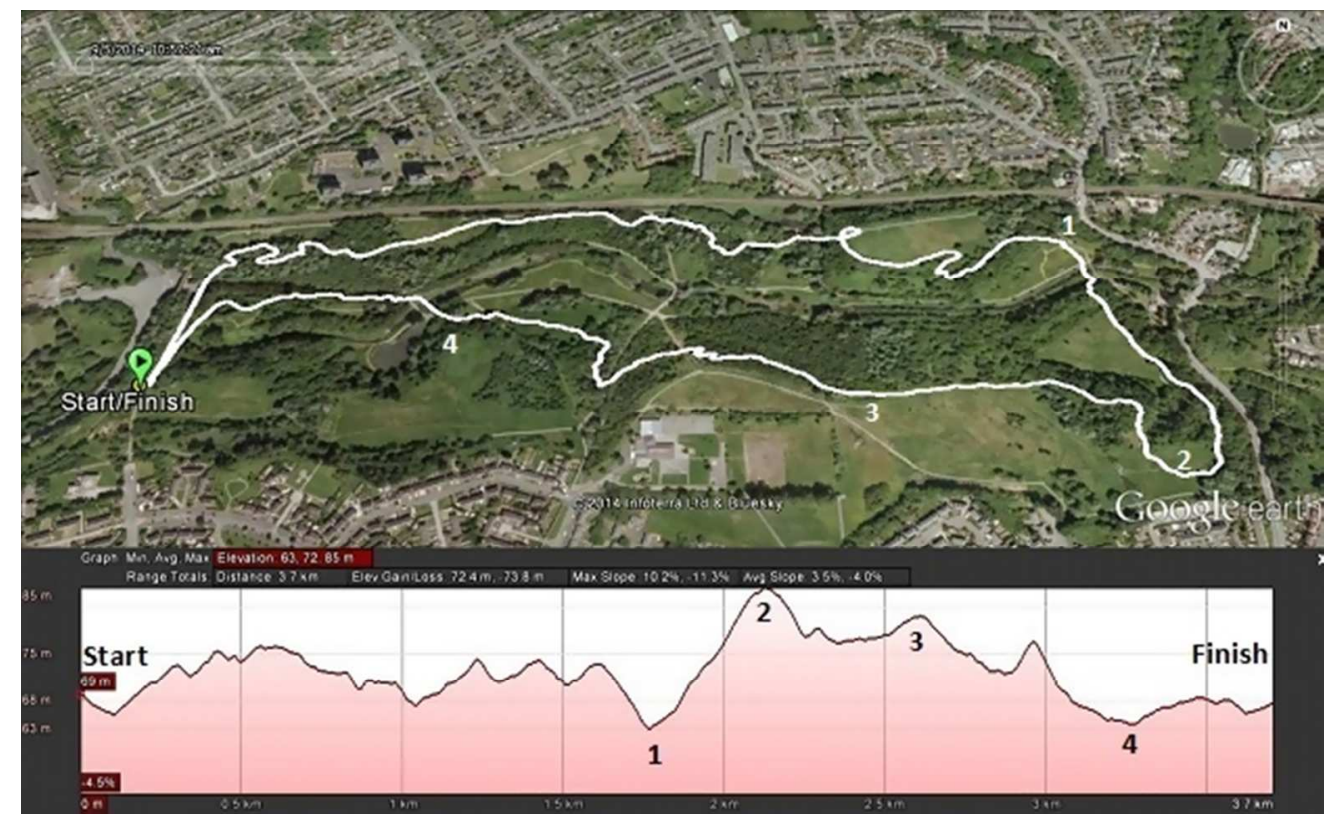

Figure 1

$164 \times 101 \mathrm{~mm}(96 \times 96$ DPI $)$

31

32

33

34

35

36

37

38

39

40

41

42

43

44

45

46

47

48

49

50

51

52

53

54

55

56

57

58

59

60

URL: http://mc.manuscriptcentral.com/rjsp 


\begin{tabular}{|c|c|c|c|}
\hline \multicolumn{4}{|l|}{ Full Lap } \\
\hline Gastrocnemius & $4.71 \pm 3.23(2.22,7.19)$ & $4.86 \pm 3.28(2.33,7.38)$ & $4.83 \pm 3.12(2.43,7.22)$ \\
\hline Vastus Lateralis & $4.56 \pm 2.54(2.61,6.52)$ & $4.94 \pm 2.99(2.64,7.23)$ & $4.62 \pm 2.31(2.84,6.40)$ \\
\hline Biceps Brachii & $1.78 \pm 1.66(0.51,3.06)^{*}$ & $1.17 \pm 0.74(0.61,1.74)^{\dagger}$ & $1.32 \pm 0.67(0.80,1.85)^{\ddagger}$ \\
\hline Triceps Brachii & $3.61 \pm 1.28(2.62,4.59)$ & $3.58 \pm 1.34(2.55,4.61)$ & $3.66 \pm 1.70(2.84,4.48)$ \\
\hline \multicolumn{4}{|l|}{ Climb } \\
\hline Gastrocnemius & $4.91 \pm 3.33(2.35,7.47)$ & $4.68 \pm 3.10(2.30,7.05)$ & $4.81 \pm 3.07(2.46,7.17)$ \\
\hline Vastus Lateralis & $4.62 \pm 2.51(2.70,6.55)$ & $4.95 \pm 3.04(2.61,7.28)$ & $4.60 \pm 2.41(2.74,6.45)$ \\
\hline Biceps Brachii & $1.43 \pm 1.04(0.63,2.22)^{*}$ & $1.18 \pm 0.87(0.51,1.85)^{\dagger}$ & $1.09 \pm 0.78(0.49,1.69)^{¥}$ \\
\hline Triceps Brachii & $3.26 \pm 1.20(2.33,4.18)$ & $3.39 \pm 1.17(2.50,4.29)$ & $3.43 \pm 1.02(2.64,4.21)$ \\
\hline \multicolumn{4}{|l|}{ Descent } \\
\hline Gastrocnemius & $4.70 \pm 3.43(2.07,7.34)$ & $4.56 \pm 3.24(2.07,7.05)$ & $4.63 \pm 3.12(2.23,7.03)$ \\
\hline Vastus Lateralis & $4.64 \pm 2.94(2.37,6.90)$ & $4.78 \pm 2.87(2.58,6.99)$ & $4.30 \pm 2.14(2.65,5.95)$ \\
\hline Biceps Brachii & $2.29 \pm 3.05(-0.06,4.63)$ & $1.19 \pm 0.74(0.62,1.76)^{\dagger}$ & $1.44 \pm 0.75(0.86,2.02)^{\ddagger}$ \\
\hline Triceps Brachii & $3.91 \pm 1.35(2.88,4.95)$ & $3.85 \pm 1.60(2.62,5.08)$ & $3.79 \pm 1.12(2.93,4.65)$ \\
\hline
\end{tabular}

URL: http://mc.manuscriptcentral.com/rjsp 


\section{6" Wheel \\ Mean \pm sd $(95 \% \mathrm{Cl})$}

\begin{abstract}
Full Lap
\end{abstract}
Gastrocnemius

Vastus Lateralis

Biceps Brachii

Triceps Brachii

Climb

Gastrocnemius

Vastus Lateralis

Biceps Brachii

Triceps Brachii

\section{Descent}

Gastrocnemius

Vastus Lateralis

Biceps Brachii

Triceps Brachii
$69.68 \pm 3.31(67.13,72.23)$

$66.73 \pm 4.27(63.45,70.01)$

$56.82 \pm 2.87(54.61,59.03)$

$57.08 \pm 7.12(51.61,62.56)$

$60.31 \pm 6.84(55.05,65.56)$

$58.05 \pm 2.20(56.36,59.74)$

$60.48 \pm 6.21(55.71,65.25)$

$64.45 \pm 5.87(59.93,68.96)$
27.5" Wheel

Mean $\pm \mathrm{sd}(95 \% \mathrm{Cl})$
29" Wheel

Mean $\pm \mathrm{sd}(95 \% \mathrm{Cl})$ 